\title{
$\mathrm{R} C \& \mathrm{C}$
}

REVISTA DE CONTABILIDADE E CONTROLADORIA

\section{AVALIAÇÃO DO SISTEMA DE CONTROLE GERENCIAL SOB A INFLUENCIA DE FATORES CONTINGENCIAIS: ESTUDO DE CASO EM UM GRUPO ECONÔMICO}

\section{EVALUATION OF THE MANAGEMENT CONTROL UNDER THE INFLUENCE OF CONTINGENCY FACTORS SYSTEM: CASE STUDY IN AN ECONOMIC GROUP}

Recebido em 25.10.2014 | Aceite final em 20.03.2016|

Nota: este artigo foi aceito pelo Editor Jorge Eduardo Scarpin e passou por uma avaliação double blind review A reprodução dos artigos, total ou parcial, pode ser feita desde que citada a fonte.

FELIPE DE OLIVEIRA SANTOS Mestre em Contabilidade e Controladoria pela UFAM || Universidade Federal do Amazonas - UFAM| Avenida General Rodrigo Octávio, 6200| Japiim | CEP: 69077000| Manaus/AM | Telefone: (92) 33213380 | Email: felipesantos@ufam.edu.br

\section{SÂMIA REGINA PICANÇO DE JESUS} Mestre em Contabilidade e Controladoria pela UFAM || Universidade Federal do Amazonas - UFAM| Avenida General Rodrigo Octávio, 6200| Japiim | CEP: 69077000| Manaus/AM | Telefone: (92) 33213380| Email: samiapicanco@ufam.edu.br

\section{WALDEMAR ANTÔNIO DA ROCHA DE SOUZA} Livre-Docente (LD) | Professor Adjunto de Finanças | Universidade Federal de Alagoas - UFAL| Faculdade de Economia, Administração e Contabilidade - FEAC| Campus A.C. Simões Av. Lourival de Melo Mota, Bloco 16, $1^{\circ}$ andar| Tabuleiro do Martins | CEP: 57072-970| Maceió/AL |

\section{TRISTÃO SÓCRATES BAPTISTA CAVALCANTE} Doutor em Engenharia de Produção pela UFSC | Professor Adjunto da UFAM | Universidade Federal do Amazonas - UFAM| Avenida General Rodrigo Octávio, 6200| Japiim | CEP: 69077000| Manaus/AM | Telefone: (92) 33054517| Email: tristaosbc@gmail.com

\section{RESUMO}

A estrutura do SCG e os artefatos de contabilidade gerencial usados dependem da habilidade de adaptação dos fatores internos às mudanças do ambiente. O objetivo da pesquisa é avaliar a influência de fatores 
contingenciais sobre a configuração e mutação do sistema de controle gerencial de um grupo econômico, classificando-se como descritiva, estudo de caso, qualitativa e quantitativa. A população alvo da pesquisa foram os diretores e gerentes de um grupo econômico, tendo sido validados 28 questionários. Por meio da estatística descritiva e da modelagem de equações estruturais (MEE), os resultados indicaram que o grupo econômico enfrenta um cenário com alto nível de complexidade e diversidade e que as estratégias mais importantes são a velocidade na entrega, o efetivo serviço de pós-venda, o canal de distribuição amplo e a produção a baixo custo, além do uso intenso de indicadores financeiros e não financeiros. O grupo econômico tem orgulho das ações sociais e ambientais que realiza, posicionando a organização entre as de melhores práticas sustentáveis, usando o marketing em favor da valorização de sua imagem e marcas. Concluiu-se que: (i) as contingências internas influenciam a configuração do SCG; (ii) as contingências internas tem baixa influência sobre as mutações do SCG; (iii) a configuração do SCG e o ambiente possuem influência direta sobre a mutação do SCG; (iv) fatores externos pouco influenciam na ocorrência dos fatores contingenciais internos e; ( $v$ ) os fatores contingenciais externos não influenciam diretamente na configuração do SCG.

Palavras-chave: Sistema de controle gerencial. Fatores contingenciais. Modelagem de equações estruturais.

\begin{abstract}
The structure of the SCG and the artifacts used managerial accounting depend on the ability to adapt to changes of the internal factors of the environment. The research objective is to evaluate the influence of contingency factors on setting and changing of the management control system of an economic group being classified as descriptive, case study, qualitative and quantitative. The target population of the survey were the directors and managers of an economic group, 28 were validated questionnaires. Using descriptive statistics and structural equation modeling (SEM) results indicated that the group faces an economic scenario with high level of complexity and diversity and that the most important strategies are speed in delivery, the effective post-service sale, the wide distribution channel and the low-cost production, besides the intense use of financial and non-financial indicators. The economic group is proud of the social and environmental actions it performs, positioning the organization among the best sustainable practices, using marketing in favor of valuing their image and brands. It was concluded that: (i) the internal configuration of contingencies influence the SGC; (ii) the internal contingencies have little influence on changes in the SGC; (iii) the configuration of the SCG and the environment have a direct influence on
\end{abstract}


the mutation of the SCG; (iv) external factors have little influence on the occurrence of the contingency factors and internal; (v) external contingency factors not directly influence the SCG setting.

Keywords: system of management control. Contingency factors. Structural equation modeling.

\section{INTRODUÇÃO}

A atualização da estrutura do sistema de controle gerencial (SCG) de uma empresa é importante para o processo decisório e precisa estar em constante mutação, adaptando-se na velocidade e forma adequada, a fim de continuar a atender as necessidades organizacionais. A constante globalização de mercados, a expansão da concorrência, o surgimento de novas tecnologias e fenômenos naturais são exemplos de rápidas transformações do ambiente corporativo que precisam ser examinadas na análise das organizações e na configuração do SCG.

Para que as mudanças ocorridas nos ambientes organizacionais atuais não prejudiquem as operações e não desviem as empresas dos objetivos estratégicos definidos, a contabilidade gerencial e os artefatos passam por mudanças de métricas de cálculo, tanto os voltados para medir e avaliar o desempenho, quanto os destinados às filosofias e aos modelos de gerenciamento. Nesse cenário, os artefatos de contabilidade gerencial evoluíram e registram foco estratégico na orientação das operações da organização.

Junqueira (2010) destacou que não existe um modelo universal ou ideal de SCG para as organizações, devido às peculiaridades dos ambientes interno e externo em que se encontra cada empresa. Desta forma, o SCG é moldado pelo ambiente e pelos fatores contingenciais que o cercam, sendo que a estrutura do SCG e os artefatos de contabilidade gerencial usados pela organização dependem da habilidade de adaptação dos fatores internos às mudanças do ambiente.

Dessa maneira, apontando a não padronização do SCG, alguns dos pontos de questionamento de estudos recentes como Junqueira (2010), Cintra (2011) e Valeriano (2012), registraram a velocidade e qualidade de adaptação do SCG das organizações pelo surgimento ou agravamento de algum fator no ambiente. Também se destacam a frequência e finalidade do uso dos artefatos de contabilidade gerencial para o processo de gerenciamento e tomada de decisão.

Ao analisar a importância de uma organização examinar os fatores contingenciais nos ambientes internos e externos e ainda, de empregar um SCG atualizado e adequado às necessidades gerenciais da organização, originou-se o objetivo geral: avaliar a relação dos fatores contingenciais com o sistema de controle gerencial de um grupo econômico.

Para responder o objetivo geral, dividiu-se em objetivos específicos: (i) Identificar como o sistema de controle gerencial é afetado pelos fatores contingenciais tratados na pesquisa; (ii) Examinar se existe associação entre o fator contingencial externo ambiente e os fatores contingenciais internos estratégia, estrutura, tecnologia da informação e responsabilidade social corporativa e; (iii) Analisar os relacionamentos existentes entre os fatores contingenciais internos e a configuração e mutação do sistema de controle gerencial do grupo econômico de grande porte. 
A pesquisa justifica-se por conta da escassez de estudos que analisem a relação entre a configuração do SCG de organizações com os fatores contingenciais que ocorrem nos ambientes internos e externos. Junqueira (2010) concluiu que eram raras as pesquisas de campo que identificavam as características do SCG das empresas brasileiras, reforçando a necessidade de pesquisar o ambiente real das organizações.

Outra justificativa da pesquisa foi a importância de estudar a influência que fatores ambientais causam na formatação da estrutura das organizações, analisando de que forma a teoria da contingência afeta a forma de configuração do SCG, detalhando a velocidade e qualidade de adaptação da unidade em relação ao ambiente.

Por fim, a presente pesquisa também se justifica pela necessidade de contribuir com o desenvolvimento de temas relacionados à contabilidade gerencial, identificando realidades e necessidades da gestão empresarial, dentro da perspectiva da teoria da contingência e da configuração do SCG e seus artefatos.

\section{FUNDAMENTAÇÃO TEÓRICA}

Valeriano (2012) afirma que uma teoria torna-se indispensável para o desencadeamento de um processo de investigação. $O$ autor respalda-se dessa premissa, partindo de que uma teoria torna-se indispensável para dar condições explicativas do fenômeno, trabalhando as causas de existirem assim e não de outra maneira. Desta forma, torna-se essencial a construção de uma fundamentação teórica de caráter explicativo para avaliar a relação dos fatores contingenciais com o SCG de um grupo econômico.

\section{TEORIA DA CONTINGÊNCIA}

O termo teoria da contingência surgiu em 1967, em decorrência de alguns fatores denominados fatores contingenciais, os quais são caracterizados por variáveis que influenciam o processo decisório e a configuração estrutural, seja no âmbito empresarial ou no pessoal.

Uma pesquisa realizada por Lawrence e Lorsch (1967), envolvendo dez empresas de três segmentos diferentes, objetivou identificar o que cada organização fazia para tratar as diversidades econômicas e de mercado. Os autores constataram que quanto maior for o grau de diferenciação interna, mais necessários serão os mecanismos de integração entre as diversas áreas da organização e que o grau de diferenciação interna dependerá do nível de incerteza do ambiente, concluindo que as organizações que apresentaram melhores desempenhos estavam com as estruturas adequadas ao ambiente, medido pelo grau ótimo de diferenciação interna adequada ao ambiente.

Thompson (1967) expandiu os achados sobre teoria da contingência e afirmou que a tarefa e a tecnologia são os principais fatores contingenciais a influenciar a estrutura organizacional, propondo um modelo com três tipos de tecnologia, a tecnologia em elos de sequencia, a tecnologia mediadora e a tecnologia intensiva. Para Rodrigues (1984), as indústrias são um exemplo da tecnologia em elos de sequencia, os bancos com serviços de intermediação entre clientes se enquadram como mediadoras e os hospitais podem ser considerados parte da tecnologia intensiva, devido ao esforço conjunto destinado a alcançar uma mudança de algum objeto. 
Segundo concluiu Espejo (2008), a teoria da contingência preconiza que cada unidade, empresarial ou não, possui um formato distinto de estrutura, portanto, a aplicação de uma mesma técnica reproduzirá níveis de desempenho diferenciados, proporcionais a cada tipo de organização.

A palavra contingência está relacionada a um grau de incerteza, ou seja, é um fator que está fora de controle de uma pessoa ou organização e no ambiente empresarial pode ser compreendida como uma variável capaz de influenciar uma organização inteira.

A teoria da contingência está fundamentada pelo estudo de teorias anteriores, principalmente pela teoria de sistemas, cujos conceitos foram e ainda são disseminados por pesquisadores em diversas áreas de estudo.

\subsubsection{A TEORIA DE SISTEMAS}

Baseado nas ciências biológicas, o pesquisador Ludwig von Bertalanffy concebeu o pensamento teórico de sistemas entre os anos de 1950 e 1960, onde descreve que para poder sobreviver, a organização deve modificar-se de acordo com o ambiente vivenciado, empregando constante interação do organismo com o ambiente externo, segundo concluiu Tureta, Rosa e Ávila (2006). Por conta desta ligação com o meio ambiente, o objetivo principal da teoria de sistemas é demonstrar que a organização deve ser capaz de se ajustar tempestivamente ao meio, a fim de buscar um equilíbrio perante os fatores que a influenciam. De acordo com os autores, existe uma clara demonstração de intercâmbio entre a organização e o ambiente, permitindo que ambos os sujeitos possam ser influenciados e influenciadores.

Dependendo do nível de equilíbrio que uma organização se enquadre em um ambiente, devido ao constante intercâmbio realizado, o ciclo de vida pode ser prolongado por meio de reorganizações estruturais e alianças, proporcionando que as organizações sobrevivam em um ambiente incerto, complexo e muito competitivo, segundo Tureta, Rosa e Ávila (2006).

Conforme Espejo (2008), as organizações se ajustam por meio da existência de um formato sistêmico, onde ocorre a identificação de subsistemas, que seriam unidades e departamentos, que se relacionam e constroem um sistema maior, que seria todo o meio ambiente que contorna a organização.

Para Tureta, Rosa e Ávila (2006), a teoria de sistemas contribuiu na formação do conceito principal da teoria da contingência, de que não há estrutura organizacional única e efetiva a todas as organizações, mas que a estrutura organizacional deve seguramente atender as exigências impostas pelo ambiente.

Sobre este conceito, pesquisas complementam a teoria da contingência, como Hannan e Freeman (1977), Tureta, Rosa e Ávila (2006) e Martins et al. (2013), informando que o cenário de constantes adaptações não depende somente das pressões incorridas sobre a estrutura organizacional, que aplicam modelos voltados à competição e seleção de populações, mas também dependem da maneira como a estrutura está disposta, dando início a estudos sobre a intitulada teoria da ecologia organizacional (TEO). 


\subsubsection{TEORIA DA ECOLOGIA ORGANIZACIONAL}

Originada na biologia, a TEO pressupõe que diversas organizações convivem em um único ambiente e competem por uma quantidade limitada de recursos, tornando por este motivo, o ambiente dinâmico. Hannan e Freeman (1977) concluem que no caso das contingências, o sucesso depende de estratégias bem executadas que conseguem mitigar os impactos ambientais, ou ainda, que realizam ajustes suaves na estrutura com o mínimo de interrupção, contudo, não há razão para acreditar que as variações estruturais dependam apenas ou principalmente do fator de adaptação. Existem algumas restrições internas a serem consideradas.

Primeiramente, existe o fato de altos investimentos terem sido realizados em plantas fabris, máquinas e qualificação de pessoal, que somados configuram a estrutura da organização. Outro ponto encontra-se nas informações que os tomadores de decisão recebem, onde por muitas vezes, o fluxo de informação não fornece dados satisfatórios e completos sobre atividades da organização ou sobre contingências ambientais enfrentadas em outras unidades.

Outra restrição importante refere-se às políticas internas, que são diretamente afetadas por mudanças estruturais e podem causar desequilíbrios indesejados por líderes internos, que mediante a uma reação negativa, tendem a gerar empecilhos suficientes para que algumas subunidades resistam a mudanças.

Por fim, os próprios regimentos internos das organizações podem vir a ser um entrave para o processo de mudança, já que são compostos por normas e procedimentos, muitas vezes culturalmente instaurados, podendo aumentar os custos relacionados à mudança, inviabilizando o processo.

Além das restrições internas, os autores informam restrições externas que podem inviabilizar o processo de mudança, como as barreiras jurídicas e fiscais, os altos preços para obter certos tipos de informações externas em cenários turbulentos e a homogeneidade da ação, onde o mesmo tipo de mudança não é replicável a todos os tipos de organizações, ou seja, o que é racional para um tomador de decisão pode não ser racional para todos.

Sob a perspectiva da TEO, a colaboração possui maior relevância, já que tende a oferecer informações mais importantes para suprir o entendimento sobre o ambiente e contribuir na administração do fato. A identificação das organizações que fazem parte do contexto ambiental, já não é mais suficiente para se adaptar de forma eficaz a uma contingência, sendo necessário se aproximar das demais organizações e aumentar o grau de relacionamento, pois no cenário atual é mais difícil se adaptar às mudanças de forma isolada, segundo Tureta, Rosa e Ávila (2006). A TEO ainda complementa a teoria da contingência em outros aspectos, informando variáveis como o processo de adaptação em diferentes etapas do ciclo de vida organizacional, a capacidade de adaptação das organizações, a limitação de decisões de gestores, a inércia e a dinâmica das populações organizacionais.

É possível identificar a amplitude que a TEO atinge ao analisar a dinâmica das populações organizacionais, pois os mercados são limitados e os recursos escassos, portanto, os mercados serão preenchidos por organizações até atingir a capacidade máxima de demanda e oferta, fazendo com que a taxa de surgimento de novas entidades dependa da densidade do mercado, segundo Wenting e Frenken (2011). 


\subsubsection{RESPONSABILIDADE SOCIAL CORPORATIVA}

As variáveis contingenciais que surgem com o passar dos anos, vem se tornando mais diversificadas, exigindo das organizações o aumento dos parâmetros de adequação e de níveis de investimento. Baseado nas ciências ambientais e na ecologia, o termo desenvolvimento sustentável foi originado por ambientalistas, segundo Cintra (2011). O termo deriva da sustentabilidade que trata da capacidade de renovação dos ecossistemas naturais a uma taxa específica. Ambos os conceitos se tornaram mais públicos com a emissão do relatório final da comissão Brundtland (ONU, 1987) e permanecem em constante aprimoramento pela comunidade mundial. Um dos termos que deriva do desenvolvimento sustentável é a responsabilidade social corporativa (RSC).

Ainda com discussões teóricas sobre a definição, abrangência e aplicação, a RSC se transformou em um tema de interesse conjunto e de controvérsias nas últimas três décadas, segundo Marrewijk (2003), Dahlsrud (2008), Machado (2010) e Cintra (2011). Quanto à abrangência do tópico, discute-se o conceito de forma fechada à economia da própria organização e aos acionistas às práticas de boa cidadania dos dias de hoje, envolvendo a responsabilidade com a sociedade em que a organização está inserida. Um dos pontos mais discutíveis consiste no fato de que nem todas as ações direcionadas à sustentabilidade objetivam ou acarretem em lucratividade para a organização.

Para conceituar, o maior objetivo da RSC consiste no fato de fazer negócios de uma forma mais ética, transparente e humanitária possível. Dentre os diversos conceitos encontrados na literatura, a definição de Marrewijk em 2003, segundo Cintra (2011), é mais abrangente e completa que os demais conceitos que surgiram sobre o tema.

Para Marrewijk (2003), as organizações, o Estado e a sociedade civil formam uma importante relação triangular, onde cada um tem um papel dentro da sociedade. O Estado é o responsável pela criação e manutenção da legislação (controle), as organizações são responsáveis por criar riqueza por meio da competição e cooperação de mercado e as estruturas da sociedade civil tem a responsabilidade de participar da sociedade com ações coletivas.

Para o autor, o papel da sociedade civil no passado apenas figurava no cenário da sociedade e não interferia na relação existente entre o Estado e as organizações, no entanto, na visão atual, com a incorporação dos conceitos de RSC, a sociedade se tornou figura ativa e indispensável para a manutenção do sistema. Com a interação entre as partes, passa a existir o desenho de uma engrenagem, onde fatores contingenciais em um ambiente reflete nos demais, em maior ou menor intensidade a depender do nível da mudança, o que direciona as organizações a ter um preparo maior para tratar e se adequar em tempo hábil e com agressividade visando a manutenção ou aumento da competitividade, conforme exposto no capítulo anterior.

Segundo Cintra (2011), atualmente existe motivos para as organizações atuarem no âmbito social, ligados ao fortalecimento da imagem perante a sociedade, interesses de longo prazo, a viabilização de estratégias, um eventual interesse dos acionistas e ainda oportunidades lucrativas que podem surgir como a prevenção de crises na organização perante o envolvimento da mesma com o interesse social da comunidade. No entanto, a atuação na esfera social também pode trazer prejuízos se a organização não estiver preparada para lidar com as peculiaridades do campo social, como o enfraquecimento da imagem nacional e internacional, o não atingimento da lucratividade máxima devido aos custos do envolvimento social e a fuga do principal objetivo, que é o lucro. 
Como o termo desenvolvimento sustentável foi originado por ambientalistas, se tornava necessário que houvesse alguma interpretação do tema para o mundo dos negócios e a linguagem empresarial. Assim, com o objetivo de sensibilizar as organizações quanto à importância do tema e quanto à mudança em escala mundial que estava ocorrendo, a consultoria britânica SustainAbility e o seu fundador John Elkington criaram o termo Triple Bottom Line (TBL).

Cintra (2011) informa que o TBL visa passar para as organizações que objetivam atender ao capitalismo sustentável, que não somente o lucro econômico é importante, mas também o valor social e ambiental que geram ou consomem ao longo do percurso a percorrer para atingir tal meta. Em linhas gerais, é a preocupação da geração atual em gerar recursos econômicos sem que este processo destrua ou limite as opções econômicas, sociais e ambientais disponíveis para as gerações futuras.

O TBL é composto por três dimensões, social, econômica e ambiental e preconiza que o sucesso organizacional de longo prazo envolve a contribuição para o desenvolvimento econômico e social da comunidade, da criação ou manutenção de um ambiente saudável e de uma sociedade estável.

\subsection{SISTEMA DE CONTROLE GERENCIAL}

Segundo Junqueira (2010) os termos, contabilidade gerencial, sistema de contabilidade gerencial, sistema de controle gerencial e controle organizacional, no campo da pesquisa em contabilidade gerencial são algumas vezes usados de forma alternada e como sinônimos. 0 autor justifica a afirmativa, uma vez que não há uma conformidade mundial acerca dos conceitos, o que é evidenciado por estudos realizados na área da contabilidade gerencial publicados nos principais periódicos internacionais, que usam os termos de forma desordenada. Optou-se nesta pesquisa, por usar o conceito amplo de sistema de controle gerencial, que engloba todos os artefatos usados na área da contabilidade gerencial.

A contabilidade gerencial pode ser definida, segundo Atkinson (2011) como o processo de identificar, mensurar, descrever e analisar as informações sobre os fatos econômicos de uma organização e ainda com os eventos ocorridos no processo de gestão, com a finalidade de gerar a informação contábil gerencial para tomada de decisões e aperfeiçoamento dos processos e o desempenho da empresa.

Para Cintra (2011), a contabilidade gerencial é o processo de identificar, mensurar, acumular, analisar, preparar, interpretar e comunicar informações que auxiliem os gestores a atingir objetivos organizacionais, deixando clara a contribuição maior da contabilidade gerencial, que é a de auxiliar na tomada de decisão por meio de informações. A autora informa ainda, que por sua vez, o controle gerencial é o conjunto de atividades a serem realizadas para garantir que os objetivos organizacionais sejam alcançados, tendo como exemplos de atividades: (i) planejar as ações da organização; (ii) coordenar as atividades da organização; (iii) comunicar a informação; (iv) avaliar a informação; (v) decidir sobre o curso das ações e; (vi) influenciar o comportamento das pessoas.

A definição de controle gerencial se remete ao domínio, segundo Cintra (2011). Para a autora, o controle gerencial pode ser entendido como o processo pelo qual os executivos influenciam outros membros, para que obedeçam as estratégias adotadas e assim assegurem que os objetivos da organização sejam atingidos. Desta forma, os procedimentos organizacionais de controle devem: (i) 
manter a viabilidade por meio do atingimento de objetivos; (ii) coordenar a integração e; (iii) adaptar-se aos fatores contingenciais internos e externos. Para a autora, são os próprios gestores os responsáveis por adotar medidas que mantenham a organização engajada aos objetivos prédefinidos.

Simons (1995) defende que para que técnicas de controle da contabilidade gerencial sejam bem implantadas, executadas e monitoradas, deve existir um equilíbrio entre as forças que impactam uma organização e o ambiente em que atua, permitindo que o SCG seja flexível ao ponto de manter o curso da organização em conformidade com as estratégias definidas.

Para Simons (1995), as técnicas de comando e controle apresentam falhas e as estratégias se desenvolvem de maneiras distintas, ora planejadas, ora emergentes. Para que os gestores das organizações possam liderar com eficiência dentro deste cenário incerto de execução de estratégias, o autor criou um modelo de controle gerencial, o Modelo de Alavancas de Controle (MAC).

O MAC vislumbra um SCG com objetivo de implantar e monitorar as estratégias da organização, considerando quatro conceitos principais: (i) valores centrais; (ii) riscos a serem evitados; (iii) incertezas estratégicas e; (iv) variáveis críticas de desempenho. Os quatro conceitos são, por sua vez, acionados por meio da operacionalização de quatro sistemas, as chamadas alavancas de controle, sendo: (i) sistemas de crenças; (ii) sistemas de limites; (iii) sistemas de controles diagnósticos e; (iv) sistemas de controles interativos.

Simons (1995) critica as organizações que traçam o planejamento e configuram o SCG assegurando que não haverá imprevistos que ameacem o transcorrer das atividades e complementa que o MAC reconhece a necessidade de balanceamento entre demandas concorrentes e que as alavancas fornecem forças positivas e negativas, assim equilibrando estas demandas.

\subsection{CONTABILIDADE GERENCIAL E SEUS ARTEFATOS}

O foco principal da contabilidade gerencial é fornecer informações para executivos, gerentes e demais funcionários que trabalham nas organizações e como forma de desempenhar suas atividades e funções, a contabilidade gerencial precisa usar métodos de mensuração e instrumentos de avaliação de desempenho, denominados como artefatos por trabalhos recentes de Espejo (2008), Junqueira (2010), Cintra (2011) e Valeriano (2012).

Outros estudos, como os de Hall et al. (2012), Frezzatti (2005), Soutes (2006), Oyadomari et al. (2008), Stroeher e Freitas (2008) e Isidoro (2012), mediram a finalidade e frequência do uso de diversos artefatos de contabilidade gerencial em empresas, identificando que a maioria das empresas pesquisadas pouco usam as informações oriundas dos artefatos para tomada de decisão, que algumas usam tais informações meramente para atendimento de obrigações legais e que outras usam na maioria artefatos considerados tradicionais.

Em 1998, o International Federation of Accountants (IFAC) publicou um trabalho sobre a contabilidade gerencial, o qual demonstrou conceitualmente os objetivos, tarefas e parâmetros da contabilidade gerencial, além de demonstrar o processo de evolução em quatro estágios, sendo: (i) até 1950, com o foco destinado à determinação do custo e do controle financeiro, por meio do uso da tecnologia do orçamento e da contabilidade de custos; (ii) entre 1950 e 1965, com o objetivo 
principal voltado para planejamento e controle gerencial, por meio do uso das técnicas de análise de decisões e da contabilidade por responsabilidade; (iii) entre 1965 e 1985, com o objetivo de reduzir perdas de recursos nos processos, enfatizando a análise de processos e o gerenciamento de custos e; (iv) de 1985 até os dias atuais, tem o foco voltado para a geração de valor para o consumidor, para os acionistas e para os demais stakeholders, além do desenvolvimento em inovação organizacional e tecnológica.

Os principais artefatos de contabilidade gerencial encontrados em pesquisas anteriores que foram identificados como ferramentas de auxílio à tomada de decisão e gerenciamento de processos, sendo classificados quanto à cronologia, que segundo Junqueira (2010), os artefatos apresentados até 1985 devem ser classificados como tradicionais e os artefatos apresentados a partir de 1985 devem ser classificados como contemporâneos. Uma breve lista de artefatos é demonstrada na Figura 1.

Figura 1: Artefatos de contabilidade gerencial.

\begin{tabular}{|c|c|c|c|}
\hline & Artefatos & $\begin{array}{c}\text { Tradicionais }-1^{\circ}, 2^{\circ} \text { e } 3^{\circ} \text { estágios } \\
\text { (até } 1985 \text { ) }\end{array}$ & $\begin{array}{c}\text { Contemporâneos }-4^{\circ} \text { estágio } \\
\text { (a partir de 1985) }\end{array}$ \\
\hline \multirow{4}{*}{$\begin{array}{l}\text { Métodos, critérios e } \\
\text { sistemas de custeio }\end{array}$} & Custeio baseado em atividades & & $\mathrm{x}$ \\
\hline & Custeio padrão & & $\mathrm{x}$ \\
\hline & Custeio por absorção & $\mathrm{x}$ & \\
\hline & Custeio variável & $\mathrm{x}$ & \\
\hline \multirow{8}{*}{$\begin{array}{c}\text { Métodos de mensuração, } \\
\text { avaliação e medidas de } \\
\text { desempenho }\end{array}$} & Análise da cadeia de valor & & $\mathrm{x}$ \\
\hline & Análise da lucratividade do produto & $\mathrm{x}$ & \\
\hline & Análise do ciclo de vida do produto & & $\mathrm{x}$ \\
\hline & Benchmarking interno e externo & & $\mathrm{x}$ \\
\hline & EVA e outras medias econômicas de desempenho & $\mathrm{x}$ & \\
\hline & Market Share & & $\mathrm{x}$ \\
\hline & Retorno sobre investimentos (ROE, ROCE, ROI, ROIC) & $\mathrm{x}$ & \\
\hline & Técnicas de orçamento de capital (VPL, TIR, payback) & & $\mathrm{x}$ \\
\hline \multirow{8}{*}{$\begin{array}{c}\text { Filosofias e modelos de } \\
\text { gestão }\end{array}$} & Análise orçamentária & $\mathrm{x}$ & \\
\hline & Balanced Scorecard (BSC) & & $\mathrm{x}$ \\
\hline & Demonstrativos contemporâneos (DFC) & & $\mathrm{x}$ \\
\hline & Demonstrativos tradicionais (BP, DRE, DVA, DMPL) & $\mathrm{x}$ & \\
\hline & Gestão baseada em atividades ( $A B M$ ) & & $\mathrm{x}$ \\
\hline & Orçamento & $\mathrm{x}$ & \\
\hline & Planejamento estratégico & $\mathrm{x}$ & \\
\hline & Sistemas de informação gerencial & $\mathrm{x}$ & \\
\hline
\end{tabular}

Fonte: Adaptado de Junqueira (2010) e Valeriano (2012).

Junqueira (2010) cita que não existe um modelo padrão de configuração do SCG e dos artefatos a serem usados por uma organização, destacando que estas características tendem a ser definidas com o amadurecimento da organização e com a capacidade de adaptação dos fatores internos às mudanças ocorridas nos ambientes em que atuam.

\section{METODOLOGIA}

Após ter sido realizada a revisão da literatura nos capítulos anteriores, assim como foram definidos o problema de pesquisa e os objetivos, a próxima etapa consiste no detalhamento dos procedimentos metodológicos usados no desenvolvimento da pesquisa, que pode ser classificada como descritiva, estudo de caso, documental, bibliográfica, de levantamento, qualitativa e quantitativa, por avaliar a influência dos diversos fatores contingenciais do ambiente na configuração do SCG e dos artefatos do grupo econômico.

Segundo Junqueira (2010), a teoria da contingência é adequada para avaliar as alterações que ocorrem na configuração do SCG. A partir desta conclusão, tornou-se possível elaborar as questões que direcionaram a pesquisa. 
Nos tópicos seguintes, são apresentados os procedimentos metodológicos usados no estudo, informando a classificação quanto à tipologia e ao tratamento estatístico, além de serem detalhados dados como a população e a forma de operacionalização do questionário usado para a coleta dos dados.

\subsection{TIPOLOGIA DA PESQUISA}

Este tópico tem por objetivo fundamentar e explicitar os procedimentos metodológicos usados no desenvolvimento da pesquisa, que pode ser classificada quanto a abordagem, como qualitativa e quantitativa. Qualitativa, pois foram realizadas análises profundas sobre o fenômeno estudado, destacando características não observadas por meio de um estudo quantitativo, e que ainda permite descrever a complexidade de determinado problema, analisar a interação de variáveis, compreender e classificar processos vividos por grupos sociais, segundo Beuren (2012).

A pesquisa também foi classificada como quantitativa, pois, segundo Beuren (2012), são usados instrumentos estatísticos no tratamento dos dados para analisar e interpretar as informações coletadas da organização e garantir a precisão dos resultados, assim descrevendo as características de uma determinada situação, medindo a hipótese levantada por meio do problema de pesquisa.

Quanto aos objetivos, a pesquisa se caracteriza como descritiva, pois objetiva avaliar a influência de fatores contingenciais sobre a configuração e mutação do sistema de controle gerencial de um grupo econômico. Segundo Beuren (2012), a pesquisa descritiva caracteriza-se em identificar, relatar e comparar características de um grupo social, sem manipulação dos dados pelo pesquisador, preservando o estudo dos fenômenos do mundo físico e humano.

Quanto aos procedimentos, a pesquisa classifica-se como estudo de caso e participante. Yin (2010), conclui que o estudo de caso objetiva compreender os fenômenos sociais complexos de uma sociedade, retendo as características significativas dos eventos da vida real.

Beuren (2012) informa que a pesquisa participante tem maior interação entre pesquisador e entrevistados de acordo com a participação do pesquisador na cultura do universo investigado, o que contribui para o alcance de resultados mais consistentes. A pesquisa é classificada ainda como documental, pois são analisadas fontes primárias e secundárias a fim de aprofundar as questões específicas.

Quanto à definição da população, o alvo da pesquisa foram os diretores e gerentes em atividade no grupo econômico, pois possuem determinadas características em comum, sendo aplicado um censo sobre a população.

O instrumento de pesquisa usado foi o questionário, estruturado por questões fechadas em escala de Likert de cinco pontos. Para Beuren (2012), o questionário tem o objetivo de obter conhecimento das pessoas quanto à opinião, interesses, percepção, expectativa e sentimentos, composto de questões claras e limitado em extensão, além de estar acompanhado de notas explicativas que possuem a natureza da pesquisa e destaquem a importância e necessidade de se obter as respostas. Para esta pesquisa, o questionário foi necessário para medir, por meio da percepção dos respondentes, a relação dos fatores contingenciais com o SCG do grupo econômico. 
Após a aplicação do questionário, os dados foram tabulados para sustentar a aplicação dos métodos estatísticos de tratamento dos dados, a serem detalhados ainda neste capítulo.

Após ter sido definida a tipologia da pesquisa e em seguida ilustrada a sequência de realização, serão descritos na próxima seção os procedimentos metodológicos.

\subsection{PROCEDIMENTO METODOLÓGICO}

O procedimento metodológico da pesquisa foi segmentado em etapas. Primeiramente foi realizada a pesquisa teórica sobre a fundamentação necessária para abordar os principais temas de acordo com cada tópico do capítulo. Na sequência, foram definidos a população e os métodos estatísticos aplicados na pesquisa, para em seguida terem sido elaboradas as questões e o formato do questionário. Após realizar estas etapas, o questionário foi enviado via email para os participantes, sendo realizadas duas cobranças após o primeiro envio. Alguns dias após a última cobrança, os dados recebidos até aquele momento foram tabulados para que os métodos estatísticos fossem aplicados e assim os dados foram tratados da maneira adequada. Por fim, ocorreu a fase de análise dos resultados da pesquisa.

\subsubsection{PESQUISA BIBLIOGRÁFICA}

A pesquisa bibliográfica foi realizada com bases recentes de pesquisas científicas publicadas em periódicos nacionais e internacionais, além de teses e dissertações de conceituadas universidades brasileiras, sempre com temas relacionados à pesquisa e às áreas de contabilidade e controladoria. Desta forma, objetivou-se consolidar a proposta desta pesquisa com as informações teóricas coletadas.

De acordo com o objetivo geral desta pesquisa que é avaliar a influência de fatores contingenciais sobre a configuração e mutação do sistema de controle gerencial de um grupo econômico, a pesquisa bibliográfica foi dividida em dois grandes temas, sendo a teoria da contingência e o SCG.

Primeiramente foi realizada uma revisão sobre a teoria da contingência, sendo realizada uma breve conceituação do tema e de sua origem, para em seguida abordar tópicos como a teoria de sistemas, a teoria da ecologia organizacional e a responsabilidade social corporativa. A teoria de sistemas contribuiu no sentido de esclarecer a importância e a influência de como os fatores dos ambientes externos e internos se relacionam. A teoria da ecologia organizacional adicionou embasamento quanto à competição entre organizações de um mesmo ambiente, limitando recursos e deixando o ambiente mais dinâmico. A responsabilidade social corporativa abordou temas atuais e relevantes quanto à expansão da consciência ambiental e da redução dos impactos ambientais causados pelo exercício das atividades e processos das organizações.

O segundo tema abordado nesta etapa foi o SCG, abordando o modelo de alavancas de Simons e a contabilidade gerencial e seus artefatos. O modelo das alavancas de Simons contribuiu no sentido de esclarecer a necessidade de o SCG possuir um equilíbrio entre as forças que incidem sobre o mesmo, de forma a estabelecer uma tolerância de aceitação ao risco tendo em vista as estratégias definidas e assim contribuir no processo de toma da decisão. Já na etapa de contabilidade gerencial e seus artefatos, foram citadas pesquisas anteriores que modelaram os conhecimentos teóricos existentes 
atualmente sobre o tema e demonstraram os principais objetivos e características de um SCG, além de identificar alguns fatores de contabilidade gerencial usados ao longo dos anos.

\subsubsection{DEFINIÇÃO DA POPULAÇÃO E DOS MÉTODOS ESTATÍSTICOS}

A população é composta pelos gerentes e diretores de um grupo econômico de grande porte com 70 anos de existência. A população foi selecionada por acessibilidade e conveniência e compreenderá os gerentes e diretores ativos do grupo econômico, sendo 54 gerentes e nove diretores, totalizando 63 respondentes. A pesquisa foi um censo, ou seja, o questionário foi enviado para toda a população, sendo considerado ao final, o número máximo de 28 questionários respondidos e validados.

Foi garantido à organização e aos gerentes e diretores respondentes o anonimato e a confidencialidade das respostas, já que os dados foram tratados e expostos de forma conjunta.

Os métodos estatísticos usados na pesquisa foram: o alfa de Cronbach, a estatística descritiva e a modelagem de equações estruturais (MEE).

A estatística descritiva foi usada para calcular as frequências das variáveis, calcular as médias, medianas e desvio padrão, sendo possível compreender melhor o comportamento dos dados por meio da identificação de tendências, variabilidades e valores atípicos, conforme Junqueira (2010).

Segundo Almeida, Santos e Costa (2010), o alfa de Cronbach deve ser usado para avaliar a confiabilidade e a realidade de um questionário a ser aplicado em uma pesquisa, tendo como fator mínimo aceitável o intervalo entre 0,60 e 0,70 pontos para as respostas. Um questionário é considerado válido e confiável quando reflete o resultado verdadeiro, garantindo que uma medida esteja livre de variância de erros aleatórios oriundos de questionários mal estruturados.

O método estatístico MEE se diferencia das demais técnicas estatísticas, pois: (i) possibilita modelar simultaneamente relações entre múltiplos constructos e entre esses constructos e seus respectivos indicadores; (ii) considera erros de mensuração no processo de estimação; (iii) usa modelos ajustados a matrizes de covariância ou correlação, sendo a covariância a estatística básica usada nos modelos.

Segundo Espejo (2008), a MEE contribui para uma melhor compreensão de estudos mais robustos na área da contabilidade gerencial, as quais necessitam de análises de relações complexas de dependência, em que variáveis ora se apresentam dependentes e ora independentes de novas relações de dependência, o que se relaciona diretamente com o objetivo desta pesquisa que é avaliar a relação dos fatores contingenciais com o SCG do grupo econômico.

Para realizar a análise fatorial, a estatística descritiva e o alfa de Cronbach, foram usados o software Microsoft Excel 2010 e o programa R versão 3.0.1 e para realizar a MEE foi usado o software SmartPLS versão 3.1.5. Um ou mais destes métodos estatísticos foram usados em pesquisa recentes de Espejo (2008), Junqueira (2010) e Cintra (2011).

\subsection{LIMITAÇÕES DA PESQUISA}

A pesquisa objetivou avaliar a influência de fatores contingenciais sobre a configuração e mutação do sistema de controle gerencial de um grupo econômico e para tal fez-se necessário estabelecer 
limitações, como a aplicação do questionário somente para os gerentes e diretores da organização, tendo em vista serem cargos de lideranças e que detém maiores condições para promover alterações no SCG de uma organização. As respostas refletem a percepção dos profissionais que responderam o questionário.

Outra limitação trata justamente do estudo da relação dos fatores contingenciais com o SCG, não abordando temas como o ciclo de vida organizacional e o desempenho da organização, por exemplo.

Foram omitidos o nome do grupo econômico, bem como das empresas que integram o grupo, as funções e nomes dos funcionários participantes, seguindo a exigência da organização.

\section{ANÁLISE DOS RESULTADOS DA PESQUISA}

Neste capítulo são apresentados os resultados da pesquisa, por meio de análises quantitativas. 0 capítulo divide-se em quatro etapas: (i) análise descritiva das variáveis, (ii) análise confiabilidade das medidas analisadas e (iii) análise da modelagem de equações estruturais.

\subsection{ANÁLISE DESCRITIVA DAS VARIÁVEIS}

A Tabela 1 apresenta as análises de frequência das variáveis do construto ambiente. Tomando como base o item 3 da escala como ponto de corte para análise das condições do ambiente de atuação do grupo econômico de grande porte pesquisado, o ambiente é considerado diversificado por $67,9 \%$ dos respondentes, complexo para $64,3 \%$, hostil para $53,6 \%$ e dinâmico e imprevisível para 39,3\%. Considerando o item 3 da escala como a variável que representa um ambiente neutro, apenas 14,3\% dos respondentes consideram o ambiente calmo, 7,1\% considera o ambiente pouco diversificado e $3,6 \%$ estável.

Tabela 1: Frequências para os construtos do ambiente

\begin{tabular}{clcccccc}
\hline & \multicolumn{1}{c}{ Em \% } & $\mathbf{5}$ & $\mathbf{4}$ & $\mathbf{3}$ & $\mathbf{2}$ & $\mathbf{1}$ & Total \\
\hline Q1Adt & Nivel de incerteza & 0 & 39,3 & 57,1 & 3,6 & 0 & $\mathbf{1 0 0}$ \\
Q2Adt & Nivel de complexidade & 3,6 & 60,7 & 35,7 & 0 & 0 & $\mathbf{1 0 0}$ \\
Q3Adt & Nivel de diversidade & 32,1 & 35,7 & 25,0 & 7,1 & 0 & $\mathbf{1 0 0}$ \\
Q4Adt & Nivel de hostilidade & 0 & 53,6 & 32,1 & 14,3 & 0 & $\mathbf{1 0 0}$ \\
\hline
\end{tabular}

Fonte: Elaborado pelo autor.

De acordo com os dados da Tabela 1, o ambiente identificado por meio das respostas obtidas no questionário, demonstra que o grupo econômico de grande porte enfrenta um cenário com alto nível de complexidade e diversidade, além de ter um elevado grau de hostilidade oriundo da força concorrencial instalada no mercado, ressaltando que nenhum respondente considerou o ambiente simples.

A Tabela 2 apresenta as análises de frequência das variáveis do construto estratégia. Por meio das respostas obtidas, verifica-se que as estratégias mais importantes para o grupo econômico de grande porte pesquisado são a velocidade na entrega, ter um efetivo serviço de pós-venda, possuir um canal de distribuição amplo e produzir a baixo custo. 
Tabela 2: Frequências para os construtos da estratégia

\begin{tabular}{|c|c|c|c|c|c|c|}
\hline Em \% & 5 & 4 & 3 & 2 & 1 & Total \\
\hline Q1a.Est. Baixo custo & 46,4 & 25,0 & 17,9 & 3,6 & 7,1 & 100 \\
\hline Q1b.Est. Produtos diferenciados & 28,6 & 39,3 & 25,0 & 7,1 & 0 & 100 \\
\hline Q1c.Est. Ampla variedade de produtos & 28,6 & 39,3 & 25,0 & 7,1 & 0 & 100 \\
\hline Q1d.Est. Baixo preço & 25,0 & 28,6 & 28,6 & 17,9 & 0 & 100 \\
\hline Q1e.Est. Vel. na introdução de novos produtos & 21,4 & 28,6 & 28,6 & 17,9 & 3,6 & 100 \\
\hline Q1f.Est. Vel. na modificação do volume ou mix & 17,9 & 28,6 & 35,7 & 10,7 & 7,1 & 100 \\
\hline Q1g.Est. Velocidade na entrega & 57,1 & 35,7 & 7,1 & 0 & 0 & 100 \\
\hline Q1h.Est. Efetivo serviço de pós-venda & 50,0 & 35,7 & 14,3 & 0 & 0 & 100 \\
\hline Q1i.Est. Canal de distribuição amplo & 64,3 & 32,1 & 3,6 & 0 & 0 & 100 \\
\hline Q1j.Est. Customização de produtos & 25,0 & 28,6 & 32,1 & 3,6 & 10,7 & 100 \\
\hline
\end{tabular}

Fonte: Elaborado pelo autor.

Por outro lado, as estratégias menos importantes na visão dos respondentes são o baixo preço, a velocidade na introdução de novos produtos, a velocidade na modificação do volume ou mix e a customização de produtos, o que demonstra que o foco estratégico do grupo econômico de grande porte está relacionado a produzir produtos a baixo custo e a vender em grandes quantidades, provavelmente devendo estas características ao perfil de franquia.

A Tabela 3 refere-se às análises de frequência das variáveis do construto estrutura. A análise das respostas obtidas demonstra que o grupo econômico de grande porte tende a adotar uma estrutura adaptável, incentivando a execução de tarefas por equipes multifuncionais, além de programas de treinamento para lideranças e liderados, o que demonstra o interesse do grupo econômico em manter os líderes aptos para o bom desempenho de suas atividades.

Outra característica identificada foi quanto ao pouco uso da estrutura divisional, onde uma mesma atividade é executada por diferentes divisões, o que estimula a gestão participativa e a gestão com poucos níveis hierárquicos, além de evidenciar a organização e divisão hierárquica de tarefas e funções.

\section{Tabela 3: Frequências para os construtos da estrutura}

\begin{tabular}{llcccccc}
\hline \multicolumn{1}{c}{ Em \% } & $\mathbf{5}$ & $\mathbf{4}$ & $\mathbf{3}$ & $\mathbf{2}$ & $\mathbf{1}$ & Total \\
\hline Q1a.Estr & Estrutura com tarefa por equipes & 21,4 & 39,3 & 35,7 & 3,6 & 0 & $\mathbf{1 0 0}$ \\
Q1b.Estr & Estrutura com tarefa por equipes multifuncionais & 11,1 & 51,9 & 22,2 & 11,1 & 3,7 & $\mathbf{1 0 0}$ \\
Q1c.Estr & Programas de treinamento de gestores & 10,7 & 57,1 & 21,4 & 7,1 & 3,6 & $\mathbf{1 0 0}$ \\
Q1d.Estr & Programas de treinamento de empregados & 14,3 & 39,3 & 28,6 & 10,7 & 7,1 & $\mathbf{1 0 0}$ \\
Q1e.Estr & Estrutura estimula gestão participativa & 11,1 & 40,7 & 29,6 & 14,8 & 3,7 & $\mathbf{1 0 0}$ \\
Q1f.Estr & Estrutura com poucos niveis hierárquicos & 3,6 & 50,0 & 28,6 & 14 & 3,6 & $\mathbf{1 0 0}$ \\
Q1g.Estr & Estrutura flexivel & 3,6 & 32,1 & 32,1 & 25 & 7,1 & $\mathbf{1 0 0}$ \\
Q1h.Estr Estrutura adaptável & 14,3 & 57,1 & 28,6 & 0 & 0 & $\mathbf{1 0 0}$ \\
Q1i.Estr & Estrutura divisional & 3,7 & 18,5 & 44,4 & 25,9 & 7,4 & $\mathbf{1 0 0}$ \\
\hline
\end{tabular}

Fonte: Elaborado pelo autor.

A Tabela 4 demonstra os dados coletados referentes aos construtos de tecnologia da informação. Destaca-se que o grupo econômico de grande porte usa frequentemente a gestão da qualidade total em seus processos, assim como o sistema integrado de gestão e a troca de dados de forma eletrônica. Oposta a esta tendência, encontram-se o pouco uso do comércio eletrônico e a gestão do tipo just in time.

Tabela 4: Frequências para os construtos de tecnologia da informação

\begin{tabular}{|c|c|c|c|c|c|c|c|}
\hline & Em \% & 5 & 4 & 3 & 2 & 1 & Total \\
\hline Q1a.Td] & Comércio eletrônico & 0 & 20,0 & 16,0 & 32,0 & 32,0 & 100 \\
\hline Q1b.Td] & Gerenciamento da relação com o cliente & 14,3 & 35,7 & 25,0 & 21,4 & 3,6 & 100 \\
\hline Q1c.Td] & Gerenciamento da cadeia de suprimentos & 11,5 & 38,5 & 34,6 & 11,5 & 3,8 & 100 \\
\hline Q1d.Td & Troca de dados de forma eletrônica & 15,4 & 42,3 & 19,2 & 19,2 & 3,8 & 100 \\
\hline Q1e.Td] & Sistema integrado de gestão & 22,2 & 51,9 & 18,5 & 7,4 & 0 & 100 \\
\hline Q1f.TdI & Just in time & 0 & 20,0 & 32,0 & 16,0 & 32,0 & 100 \\
\hline Q1g.Td] & Gestão da qualidade total & 23,1 & 30,8 & 42,3 & 3,8 & 0 & 100 \\
\hline
\end{tabular}

Fonte: Elaborado pelo autor. 
A Tabela 5 demonstra as análises de frequência das variáveis do construto de responsabilidade social corporativa. Conforme dados coletados por meio do questionário, os respondentes entendem que o mais importante para a empresa é implantar ações de RSC devido à exigências, seja por legislação ou seja por franquia.

Tão importante quanto implantar as ações de RSC, na opinião dos respondentes, é ter orgulho das ações sociais e ambientais, além de atuar junto à sociedade e assim poder posicionar a empresa entre as organizações com as melhores práticas sustentáveis e usar o marketing em favor da valorização da imagem da empresa e da marca perante a sociedade, o que demonstra o compromisso do grupo econômico com o ambiente em que atua.

Tabela 5: Frequências para os construtos da responsabilidade social corporativa

\begin{tabular}{|c|c|c|c|c|c|c|}
\hline Em \% & 5 & 4 & 3 & 2 & 1 & Total \\
\hline Q1a.RSC Implantar ações por exigência de legislação & 32,1 & 57,1 & 10,7 & 0 & 0 & 100 \\
\hline Q1b.RSC Implantar ações por exigencia de franquias & 40,7 & 48,1 & 11,1 & 0 & 0 & 100 \\
\hline Q1c.RSC Usufruto de beneficios econômicos & 12,5 & 58,3 & 20,8 & 8,3 & 0 & 100 \\
\hline Q1d.RSC Demonstrar que o produto é sustentável e a & 30,8 & 38,5 & 23,1 & 3,8 & 3,8 & 100 \\
\hline Q1e.RSC Agir antes da obrigatoriedade de leis & 26,9 & 34,6 & 23,1 & 11,5 & 3,8 & 100 \\
\hline Q1f.RSC Atuar junto à sociedade & 32,1 & 46,4 & 10,7 & 10,7 & 0 & 100 \\
\hline Q1g.RSC Ter orgulho de suas ações sociais e ambientais & 26,9 & 57,7 & 11,5 & 3,8 & 0 & 100 \\
\hline Q1h.RSC Usar o marketing para valorizar a empresa & 25,9 & 48,1 & 14,8 & 7,4 & 3,7 & 100 \\
\hline $\begin{array}{l}\text { Q1i.RSC } \begin{array}{l}\text { Posicionar a empresa entre as organizações com as } \\
\text { melhores práticas sustentáveis }\end{array}\end{array}$ & 28,0 & 48,0 & 16,0 & 8,0 & 0 & 100 \\
\hline Q1j.RSC Investir para adotar práticas ligadas à RSC & 20,0 & 48,0 & 24,0 & 8,0 & 0 & 100 \\
\hline $\begin{array}{l}\text { Q2a.RSC Sistema de informação possui dados relacionados } \\
\text { à relatórios de RSC }\end{array}$ & 4,3 & 52,2 & 21,7 & 21,7 & 0 & 100 \\
\hline Q2b.RSC $\begin{array}{l}\text { Sistema de informação possui dados não } \\
\text { financeiros relacionados à relatórios de RSC }\end{array}$ & 4,3 & 56,5 & 17,4 & 21,7 & 0 & 100 \\
\hline Q2c.RSC $\begin{array}{l}\text { Sistema de informação é importante para a coleta, } \\
\text { mensuração e controle das ações de RSC }\end{array}$ & 20,8 & 50,0 & 20,8 & 8,3 & 0 & 100 \\
\hline Q2d.RSC $\begin{array}{l}\text { Preparar sistema de informação para lidar com o } \\
\text { aumento de demandas sobre RSC }\end{array}$ & 13,0 & 30,4 & 39,1 & 17,4 & 0 & 100 \\
\hline
\end{tabular}

Fonte: Elaborado pelo autor.

Apesar de terem apresentado uma quantidade expressiva de respostas concordando com a importância, os itens com menor importância na visão dos respondentes foi a necessidade de o sistema de informação contemplar os dados financeiros e contábeis relacionados à divulgação de relatórios de RSC, assim como os dados físicos não financeiros. Tal resultado pode estar relacionado à dificuldade de mensurar o retorno de ações voltadas à RSC.

As Tabelas 6 e 7 demonstram as análises de frequência das variáveis do construto de configuração do sistema de controle gerencial, sendo a Tabela 6 referente aos artefatos e indicadores financeiros e econômicos usados e a Tabela 7 referente aos artefatos e indicadores não financeiros usados. 
Tabela 6: Frequências para os construtos da configuração do SCG para indicadores financeiros

\begin{tabular}{|c|c|c|c|c|c|c|}
\hline $\mathrm{Em} \%$ & 5 & 4 & 3 & 2 & 1 & Total \\
\hline Q1a.SCG Planejamento estratégico formal & 60,7 & 35,7 & 3,6 & 0 & 0 & 100 \\
\hline Q1b.SCG Técnicas de orçamento de capital & 44,4 & 44,4 & 11,1 & 0 & 0 & 100 \\
\hline Q1c.SCG Retorno sobre investimentos & 52,0 & 44,0 & 4,0 & 0 & 0 & 100 \\
\hline Q1d.SCG Gerenciamento por projeto & 28,6 & 53,6 & 10,7 & 7,1 & 0 & 100 \\
\hline Q1e.SCG Orçamento & 71,4 & 25,0 & 3,6 & 0 & 0 & 100 \\
\hline Q1f.SCG Custeio por absorção & 35,0 & 45,0 & 10,0 & 10,0 & 0 & 100 \\
\hline Q1g.SCG Custeio baseado em atividades & 9,1 & 45,5 & 31,8 & 4,5 & 9,1 & 100 \\
\hline Q1h.SCG Custeio variável & 40,0 & 52,0 & 8,0 & 0 & 0 & 100 \\
\hline Q1i.SCG Custeio padrão (custo meta) & 56,0 & 40,0 & 4,0 & 0 & 0 & 100 \\
\hline Q1j.SCG Gestão baseada em atividades & 30,0 & 30,0 & 30,0 & 5,0 & 5,0 & 100 \\
\hline Q1k.SCG Análise volume/margem de contribuição/lucro & 80,8 & 11,5 & 7,7 & 0 & 0 & 100 \\
\hline Q11.SCG Análise do ciclo de vida do produto & 28,6 & 28,6 & 19,0 & 14,3 & 9,5 & 100 \\
\hline Q1m.SCG Análise da lucratividade do produto & 55,6 & 40,7 & 3,7 & 0 & 0 & 100 \\
\hline Q1n.SCG Análises econômicas de desempenho & 56,0 & 36,0 & 8,0 & 0 & 0 & 100 \\
\hline Q10.SCG Análise da cadeia de valor & 43,5 & 39,1 & 8,7 & 8,7 & 0 & 100 \\
\hline Q1p.SCG Balanced Scorecard & 21,7 & 52,2 & 17,4 & 4,3 & 4,3 & 100 \\
\hline Q1q.SCG Balanço patrimonial & 59,3 & 37,0 & 3,7 & 0 & 0 & 100 \\
\hline Q1r.SCG Demonst. resultado do exercicio & 74,1 & 18,5 & 3,7 & 0 & 3,7 & 100 \\
\hline Q1s.SCG Demonst. mutações do patrimônio liquido & 36,4 & 54,5 & 9,1 & 0 & 0 & 100 \\
\hline Q1t.SCG Demonst. valor adicionado & 42,9 & 38,1 & 19,0 & 0 & 0 & 100 \\
\hline Q1u.SCG Demonst. fluxo de caixa (direto e indireto) & 72,0 & 24,0 & 4,0 & 0 & 0 & 100 \\
\hline
\end{tabular}

Fonte: Elaborado pelo autor.

Conforma Tabela 6, os artefatos e indicadores financeiros mais usados pela empresa são: planejamento estratégico formal, retorno sobre investimentos, orçamento, custeio variável, custeio padrão, análise do volume/margem de contribuição/lucro, análise da lucratividade do produto, análises econômicas de desempenho, balanço patrimonial, demonstração do resultado do exercício, mutações do patrimônio líquido e fluxos de caixa, direto e indireto. Todos estes itens foram citados como importantes ou essenciais por mais de $90 \%$ dos respondentes, o que demonstra a importância da contabilidade gerencial e do SCG para o grupo econômico pesquisado.

Os artefatos e indicadores financeiros menos usados pela empresa, na visão dos respondentes, são: a análise do ciclo de vida do produto, o custeio baseado em atividades, o custeio por absorção e a gestão baseada em atividades. Tanto o custeio baseado em atividades quanto a gestão baseada em atividades, são métodos com alto nível de detalhamento, podendo se tornar onerosos para a organização e talvez por este motivo o grupo econômico considere o custeio variável e o custeio padrão mais importantes para a sua realidade.

Tabela 7: Frequências para os construtos da configuração do SCG para indicadores não financeiros

\begin{tabular}{|c|c|c|c|c|c|c|}
\hline Em \% & 5 & 4 & 3 & 2 & 1 & Total \\
\hline Q2a.SCG Pesquisa de satisfação dos clientes & 44,4 & 37,0 & 11,1 & 7,4 & 0 & 100 \\
\hline Q2b.SCG Avaliação dos fornecedores & 16,0 & 56,0 & 20,0 & 8,0 & 0 & 100 \\
\hline Q2c.SCG Market share & 77,8 & 18,5 & 3,7 & 0 & 0 & 100 \\
\hline Q2d.SCG Satisfação dos empregados & 44,4 & 37,0 & 11,1 & 7,4 & 0 & 100 \\
\hline Q2e.SCG Tempo médio de retenção de funcionários & 23,1 & 53,8 & 15,4 & 7,7 & 0 & 100 \\
\hline Q2f.SCG Aval. do desempenho por equipes de trabalho & 33,3 & 37,0 & 25,9 & 3,7 & 0 & 100 \\
\hline Q2g.SCG Benchmarking interno & 23,1 & 38,5 & 30,8 & 7,7 & 0 & 100 \\
\hline Q2h.SCG Benchmarking externo & 40,7 & 33,3 & 18,5 & 7,4 & 0 & 100 \\
\hline
\end{tabular}

Fonte: Elaborado pelo autor.

De acordo com os dados demonstrados na Tabela 7, todos os artefatos e indicadores não financeiros usados pela empresa são importantes ou essenciais, com destaque para o market share e o grau de satisfação dos clientes e empregados, o que demonstra a preocupação do grupo econômico na relação com os stakeholders. Apesar de todos indicadores terem sido citados como importantes, o benchmarking interno foi o que demonstrou ser menos relevante para os respondentes. 
A Tabela 8 demonstra as análises de frequência das variáveis do construto de mutação do SCG. Neste bloco de perguntas, foi questionado aos respondentes quanto ao grau de concordância sobre cada item, onde as maiores frequências surgiram na fundamentação das decisões sobre as metas do planejamento, na ação rápida para aproveitar oportunidades e na agilidade para neutralizar ameaças. $\mathrm{O}$ item com menor frequência de concordância foi a possibilidade de assumir riscos ao aproveitar uma oportunidade. Outro resultado relevante no construto de mutação do SCG foi a média de $33 \%$ para as respostas neutras, o que demonstra certa indecisão por parte dos respondentes.

\section{Tabela 8: Frequências para os construtos da mutação do SCG}

\begin{tabular}{|c|c|c|c|c|c|c|}
\hline $\mathrm{Em} \%$ & 5 & 4 & 3 & 2 & 1 & Total \\
\hline Q1a.MSCG Assumir riscos ao aproveitar uma oportunidade & 11,1 & 40,7 & 40,7 & 7,4 & 0 & 100 \\
\hline $\begin{array}{l}\text { A favor da modernização de artefatos de contabilidade gerencial } \\
\text { da organização }\end{array}$ & 23,1 & 38,5 & 30,8 & 3,8 & 3,8 & 100 \\
\hline Q1c.MSCG Neutraliza uma ameaca rapidamente & 7,4 & 59,3 & 33,3 & 0 & 0 & 100 \\
\hline Q1d.MSCG Toma rapidamente as ações para aproveitar uma oportunidade & 7,4 & 59,3 & 29,6 & 3,7 & 0 & 100 \\
\hline Q1e.MSCG Sempre fundamenta as decisões sobre as metas do planejamento & 18,5 & 55,6 & 25,9 & 0 & 0 & 100 \\
\hline $\begin{array}{l}\text { Q1f.MSCG } \\
\text { Adequar rapidamente o SCG mediante uma ameaça ou } \\
\text { oportunidade }\end{array}$ & 7,7 & 50,0 & 38,5 & 0 & 3,8 & 100 \\
\hline
\end{tabular}

Fonte: Elaborado pelo autor.

A seguir, serão apresentados os resultados obtidos por meio da análise da modelagem de equações estruturais para o grupo econômico de grande porte.

\subsection{ANÁLISE DA CONFIABILIDADE DAS MEDIDAS ANALISADAS}

Como forma de estimar a confiabilidade do questionário aplicado na pesquisa, adotou-se o Alfa de Cronbach, onde segundo Hora, Monteiro e Arica (2010), o alfa mede a correlação entre as respostas de um questionário por meio da análise do perfil das respostas dadas pelos respondentes, tratandose de uma correlação média entre perguntas. Segundo os autores, o valor mínimo aceitável para um questionário ser considerado confiável é no intervalo entre 0,60 e 0,70, porém um questionário só é inaceitável quando o valor mínimo é inferior a 0,50, o que não permite que se façam inferências sobre a dimensão do questionário. Na presente pesquisa, o Alfa de Cronbach calculado para todas as variáveis em análise foi de 0,968 , o que demonstra um alto grau de consistência do questionário.

Analisando separadamente cada construto ou variável latente, observam-se os resultados conforme Tabela 9.

\section{Tabela 9: Alfa de Cronbach por construto}

\begin{tabular}{lc}
\hline \multicolumn{1}{c}{ Construtos } & Alfa de Cronbach \\
\hline Geral & 0,968 \\
\hline Ambiente de atuação & 0,443 \\
\hline Estratégia & 0,742 \\
\hline Estrutura & 0,793 \\
\hline Tecnologia da informação & 0,804 \\
\hline Responsabilidade social corporativa & 0,907 \\
\hline Configuração do sistema de controle gerencial & 0,966 \\
\hline Mutação do sistema de controle gerencial & 0,729 \\
\hline
\end{tabular}

Fonte: Elaborado do autor

Verifica-se que o construto com maior grau de confiabilidade é a configuração do SCG $(0,966)$, seguido pelo construto das variáveis de $\operatorname{RSC}(0,907)$ e por tecnologia da informação $(0,804)$. Todos os 
construtos apresentam intervalos de confiança satisfatórios para fazer inferências sobre os mesmos, exceto o construto de ambiente $(0,443)$.

\subsection{ANÁLISE DA MODELAGEM DE EQUAÇÕES ESTRUTURAIS}

A presente pesquisa usou a modelagem de equações estruturais (MEE) como técnica estatística, o que tornou possível modelar simultaneamente as relações entre múltiplos construtos e seus respectivos indicadores, assim contribuindo para uma melhor compreensão de estudos mais robustos na área da contabilidade gerencial. Os estudos em contabilidade gerencial apresentam variáveis com relações complexas de dependência, sendo estas por vezes dependentes e por vezes independentes em outras relações, ou seja, a MEE possibilita o teste simultâneo das séries de relações, conforme Espejo (2008) e Brambilla (2011).

O diagrama de caminhos foi descrito conforme Figura 11, onde as setas retilíneas representam o impacto de variáveis independentes sobre as variáveis dependentes e as setas curvilíneas representam a correlação entre as variáveis.

Figura 2: Modelo teórico da pesquisa

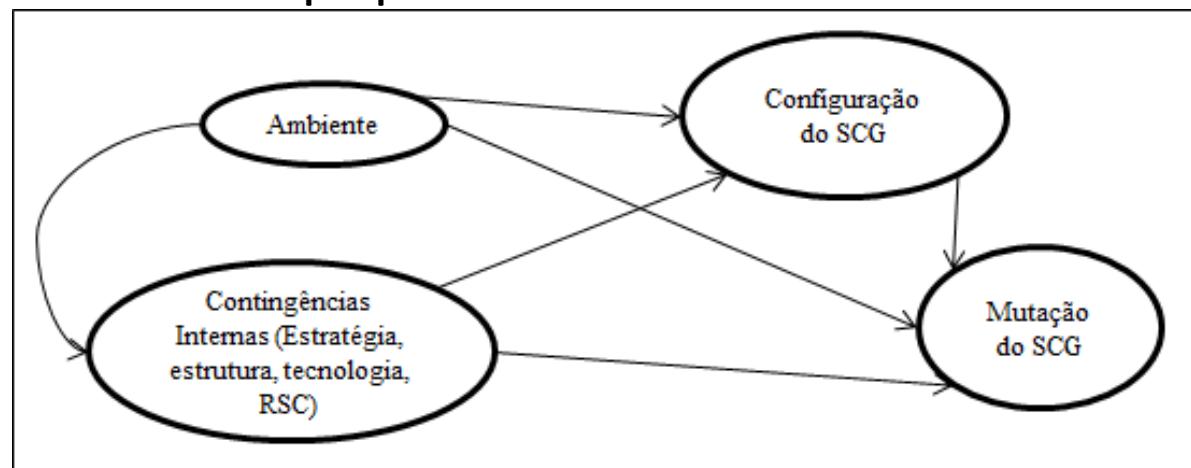

Fonte: Elaborado pelo autor.

Diante deste contexto, se tornou possível descrever o modelo teórico da pesquisa, conforme abaixo:

a. O ambiente é uma variável independente que se relaciona com variáveis contingenciais internas do grupo econômico, com a configuração e com a mutação do SCG;

b. As variáveis contingenciais internas do grupo econômico são independentes da configuração e da mutação do SCG e dependentes da variável ambiente;

c. A configuração do SCG possui relação de dependência com a variável ambiente e com as variáveis internas do grupo econômico, sendo ainda a variável explicativa na sua relação com a variável de mutação do SCG.

O modelo teórico envolvendo a técnica estatística MEE foi validado por meio do software SmartPLS

3.1.5. Pesquisas anteriores realizadas no Brasil usaram o mesmo software, como Espejo (2008), Junqueira (2010) e Cintra (2011). O SmartPLS permite a análise em construtos teóricos que apresentam-se do tipo reflexivo e formativo. A principal diferença consiste na direção das setas entre o construto teórico e as variáveis, onde no tipo reflexivo as setas saem do construto teórico e vão em direção às variáveis (ambiente) e no tipo formativo, as setas saem das variáveis e chegam ao construto teórico (contingências internas, configuração do SCG e mutação do SCG). 
A Figura 12 demonstra o modelo estrutural de construtos do grupo econômico de grande porte. Os indicadores são representados pelos retângulos e as variáveis latentes ou construtos são representados pelas esferas. Os números nas setas que ligam as esferas representam o coeficiente da equação e os números dentro das esferas representam o R2, que se refere à proporção que uma alteração na variável dependente é explicada pela variação nas variáveis independentes.

Ao analisar a associação direta entre o ambiente e a configuração do SCG, constatou-se que esta não foi significativa. A insignificância desta relação representa que a influência das contingências externas o ambiente na configuração do SCG ocorre de maneira indireta, onde o ambiente influencia os fatores contingenciais internos do grupo econômico, que por sua vez influenciam a configuração do SCG. O fato de o grupo econômico ser uma organização já consolidada em seus 70 anos de existência e de ser franqueado de marcas consagradas nos mercados em que atua, tende a justificar a baixa influencia neste quesito, uma vez que a configuração do SCG foi boa parte modelada no passado. Apenas o surgimento de uma variável nova no ambiente externo poderia trazer grandes impactos na configuração do SCG, fazendo-se elevar a significância na correlação.

\section{Figura 3: Modelo estrutural de construtos}

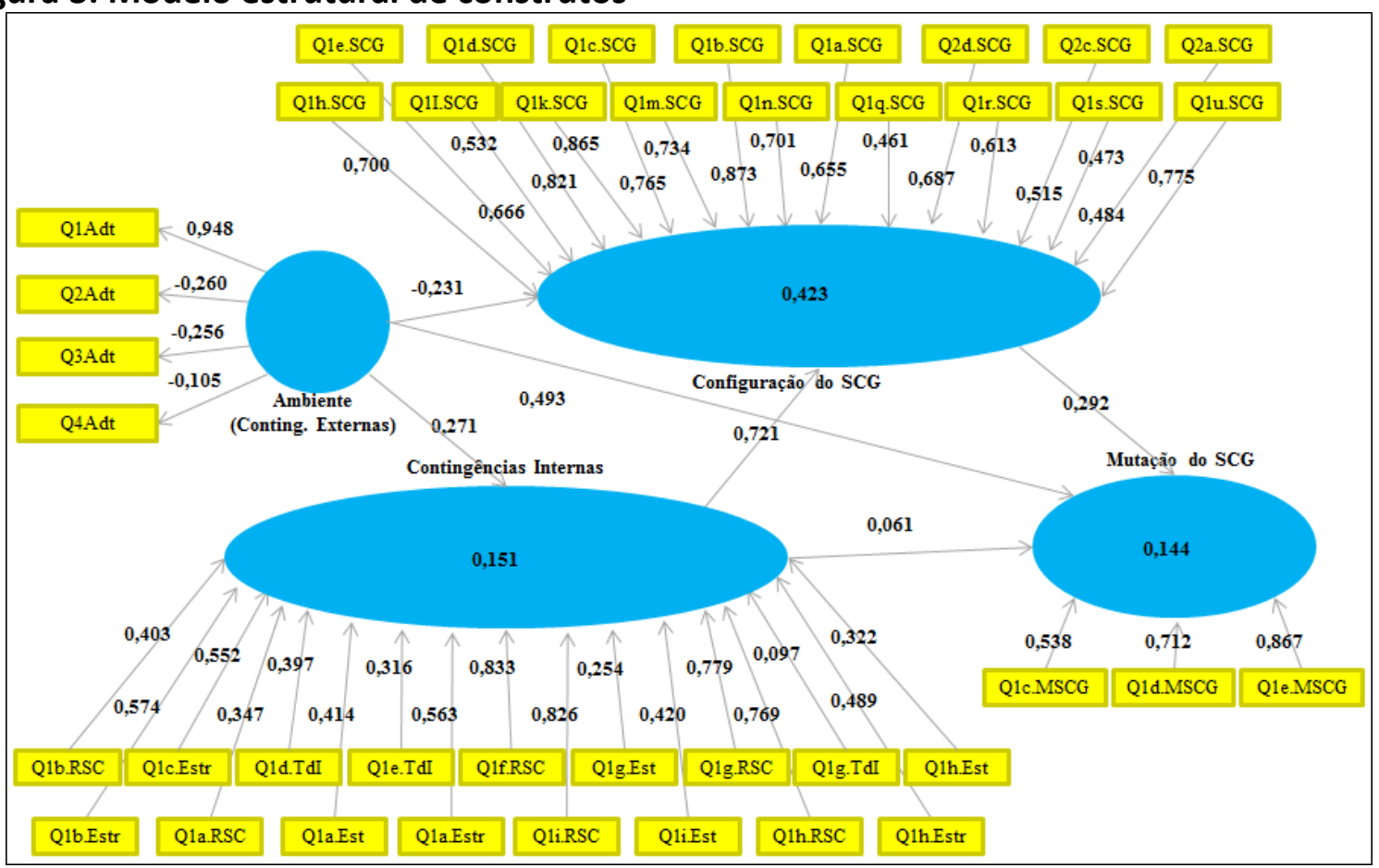

Fonte: Elaborado pelo autor.

A Figura 12 demonstra que o construto ambiente do grupo econômico de grande porte é mais afetado pelo nível de incerteza $(0,948)$ do que pelos níveis de complexidade, diversidade e hostilidade. De acordo com Junqueira (2010), a característica é mais encontrada em empresas de grande porte e industriais, onde supõe-se que empresas com estas características atuem em ambientes menos diversificados, com pouca possibilidade para novos entrantes e por isso são afetadas em maior grau pelas incertezas e complexidades relacionadas a economia, aos fornecedores, ao Governo, à inflação, a logística, as políticas governamentais, as taxas de câmbio, dentre outros.

As variáveis de estratégia, estrutura e RSC se apresentaram com as associações mais significativas no construto das contingências internas do grupo econômico, pois apresentaram os 
maiores coeficientes de equação relacionados. Dentro da variável estratégia, destacou-se a necessidade do grupo econômico fornecer produtos a baixo custo e possuir um canal de distribuição amplo e com capacidade de disponibilizar rapidamente o produto para o cliente, o que pode estar relacionado às características dos produtos que o grupo econômico comercializa.

Na variável estrutura, destacou-se o uso de equipes multifuncionais de trabalho para a execução de tarefas, os programas de qualificação dos gestores e a estrutura funcional ou adaptável. Na variável de RSC, os resultados apontaram para a importância de fatores como a responsabilidade de atuar junto à sociedade, zelar por gerações futuras, ter orgulho de ações sociais e ambientais, usar o marketing como ferramenta de valorização das ações voltadas à RSC e de posicionar o grupo econômico entre as organizações com as melhores práticas sustentáveis, o que demonstra que o grupo econômico se importa em contribuir para a melhoria das condições de vida da sociedade e dos locais onde atua.

Quanto ao construto de configuração do SCG, quase todas as variáveis quantitativas e qualitativas do SCG apresentaram associações significativas, ou seja, quase todos os artefatos contábeis tem uso intenso pelo grupo econômico de grande porte. Alguns dos artefatos têm obrigatoriedade legal, no entanto, a maioria não tem obrigatoriedade, o que demonstra o alto nível de aplicabilidade da contabilidade gerencial no dia a dia da organização. Segundo Junqueira (2010), empresas industriais respondem às mudanças nos fatores contingenciais alterando mais o uso dos artefatos qualitativos do SCG do que os quantitativos, demonstrando que mudanças nas variáveis contingenciais conduzem a uma maior confiança na informação contábil não financeira.

A mutação do SCG está associada à configuração do SCG do grupo econômico de grande porte, sendo possível citar que a organização toma rapidamente as ações necessárias para neutralizar uma ameaça, assim como para aproveitar uma oportunidade, sempre fundamentando as decisões sobre as metas de planejamento.

A matriz de correlação entre os construtos é demonstrada na Tabela 10. Verifica-se que é alta a correlação entre as contingências internas e a configuração do SCG $(72,1 \%)$, demonstrando assim a forte influência que as contingências internas possuem na configuração do SCG do grupo econômico de grande porte, ou seja, as alterações ocorridas na estrutura, estratégia, tecnologia da informação e RSC influenciam fortemente os indicadores contábeis, financeiros e não financeiros da organização.

Tabela 10: Correlações de MEE entre os construtos

\begin{tabular}{lcccc}
\hline & Ambiente & $\begin{array}{c}\text { Contingências } \\
\text { internas }\end{array}$ & $\begin{array}{c}\text { Configuração } \\
\text { do SCG }\end{array}$ & $\begin{array}{c}\text { Mutação } \\
\text { do SCG }\end{array}$ \\
\hline Ambiente & 1 & 0,271 & $-0,231$ & 0,493 \\
Contingências internas & & 1 & 0,721 & 0,061 \\
\hline Configuração do SCG & & & 1 & 0,292 \\
Mutação do SCG & & & & 1 \\
\hline
\end{tabular}

Fonte: Elaborado pelo autor

A correlação entre a mutação do SCG e o ambiente não é a mais elevada (49,3\%), mas sugere que os fatores que impactam o ambiente de atuação da organização, também trazem efeitos nos processos de mutação do SCG, uma vez que há uma aceitação por parte dos respondentes em aproveitar oportunidades e neutralizar ameaças sempre que identificadas. $O$ resultado demonstra que uma contingência externa pode impactar diretamente na mutação do SCG, 
de forma que o grupo econômico aproveite uma oportunidade ou neutralize uma ameaça rapidamente.

Em menor expressividade, a correlação entre a configuração e a mutação do SCG $(29,2 \%)$ sugere a associação entre os artefatos contábeis e a mutação do SCG do grupo econômico, o que significa dizer que somente $30 \%$ das mudanças que ocorrem na configuração do SCG de fato afetam a mutação da organização. Tal resultado pode estar relacionado à experiência que o grupo econômico possui no mercado, assim como a solidez das marcas que são franqueadas por ele.

Outro resultado menos expressivo, porém relevante, é a correlação entre o ambiente e as contingências internas $(27,1 \%)$, onde se sugere que as contingências externas influenciam em baixo grau as contingências internas, contrariando achados na literatura moderna. Apesar de Junqueira (2010) ter concluído que o estágio do ciclo de vida organizacional (CVO) pouco influencia no estudo de correlações entre construtos, o fato de o grupo econômico possuir 70 anos de existência e trabalhar com marcas consagradas nacional e internacionalmente, sugere que as contingências externas que surgiram ao longo de sua existência já influenciaram as contingências internas, como a estratégia, estrutura e a tecnologia da informação e, portanto, somente novos fatores externos poderiam impactar em maior grau as contingências internas da organização.

As contingências internas pouco influenciam na mutação do SCG, conforme grau de correlação calculado entre os dois construtos $(6,1 \%)$ e por fim, há baixa correlação entre o ambiente e a configuração do SCG $(-23,1 \%)$, demonstrando que o que de fato influencia na configuração do SCG do grupo econômico de grande porte são as contingências internas e não as externas. Tal resultado demonstra que não ocorrem modificações na estrutura de contabilidade gerencial e dos indicadores financeiros e não financeiros da organização diretamente por meio dos fatores contingenciais externos, mas sim por meio das adequações realizadas nos fatores contingenciais internos, como estratégia e a estrutura.

\section{CONCLUSÕES ERECOMENDAÇÕES}

O objetivo deste capítulo é apresentar as conclusões da pesquisa, citar os pontos importantes das análises dos resultados, citar as principais limitações da metodologia adotada e sugerir opções para futuras pesquisas e discussões a fim de dar sequência no estudo do tema ou ainda expandir a metodologia.

A seguir são apresentadas as principais conclusões da pesquisa.

\subsection{CONCLUSÕES DA PESQUISA}

A pesquisa objetivou avaliar a influência de fatores contingenciais sobre a configuração e mutação do sistema de controle gerencial de um grupo econômico. Desta forma, foi identificado como o sistema de controle gerencial é afetado pelos fatores contingenciais tratados na pesquisa. Em seguida, foi examinado se existe associação entre o fator contingencial externo ambiente e os fatores contingenciais internos estratégia, estrutura, tecnologia da informação e responsabilidade social corporativa. Por fim, foram analisados os relacionamentos existentes entre os fatores contingenciais internos e a configuração e mutação do sistema de controle gerencial do grupo econômico de grande porte. 
Concluiu-se que os fatores contingenciais internos (estratégia, estrutura, tecnologia da informação e RSC) possuem elevado grau de influência sobre a configuração do SCG da organização, confirmando os resultados encontrados em pesquisa anterior (JUNQUEIRA, 2010), ou seja, o conjunto de variáveis contingenciais internas do grupo econômico influencia diretamente nos artefatos contábeis e nos indicadores financeiros e não financeiros do SCG da organização. O fato de os respondentes citarem quase todos os artefatos de contabilidade gerencial como importantes ou essenciais, demonstra a capacidade do grupo econômico gerenciar suas atividades por meio de indicadores financeiros e não financeiros.

Conclui-se também que o construto das contingências internas tem baixa influência sobre o construto das mutações do SCG. A influência sobre tal construto ocorre de maneira indireta, por meio da configuração do SCG, dos artefatos contábeis e dos indicadores financeiros e não financeiros usados pela organização.

Os construtos que possuem influência direta sobre a mutação do SCG são a configuração do SCG e o ambiente. A configuração do SCG impacta na mutação devido ao uso intenso ou menos intenso de indicadores financeiros e não financeiros necessários, já o ambiente impacta diretamente a mutação, pois há relação direta no aproveitamento de oportunidades e neutralização de ameaças que são identificadas no ambiente de atuação da organização. Conclui-se que as contingências externas ocorridas no ambiente de atuação do grupo econômico, são rapidamente identificadas e as ações são prontamente tomadas, seja para aproveitar uma oportunidade, seja para neutralizar uma ameaça, agindo sempre com a ressalva de as ações tomadas estarem de acordo com o planejamento estratégico da organização.

Quanto à relação entre o ambiente (fatores contingenciais externos) e os fatores contingenciais internos da organização, é possível concluir que há relação, porém menos expressiva, ou seja, os fatores externos pouco influenciam na ocorrência dos fatores contingenciais internos do grupo econômico. A incerteza, a complexidade, a diversidade e a hostilidade do ambiente de atuação da organização influenciam em menor grau nos fatores contingenciais internos, como a estrutura, estratégia, tecnologia da informação e RSC. Tal conclusão está relacionada ao fato de o grupo econômico objeto deste estudo, ter 70 anos de existência e ser franqueado de marcas consagradas nacional e internacionalmente, o que significa dizer que os fatores contingenciais internos já foram bastante modificados por consequência de contingências externas no passado, onde atualmente, somente novas contingências externas poderiam influenciar nesta relação, tornando-a mais expressiva. Este resultado contraria os achados de Junqueira (2010), que concluiu que o estágio de CVO que se encontra uma empresa, pouco ou nada influencia na correlação entre construtos.

A relação direta entre o ambiente e a configuração do SCG foi insignificante, ou seja, os fatores contingenciais externos não influenciam diretamente na configuração e indicadores financeiros e não financeiros do SCG do grupo econômico. Tal relação ocorre de maneira indireta, onde o ambiente impacta os fatores contingenciais internos para em seguida, estes influenciarem a configuração do SCG. Novamente a conclusão está ligada ao estágio de CVO que o grupo econômico passa, atualmente com 70 anos de existência, assim como, pela solidez das marcas e produtos os quais a organização comercializa.

Comum a grandes empresas industriais, o nível de incerteza do mercado de atuação foi a variável mais influente dentro do construto de ambiente, supondo-se que empresas com esta característica 
atuem em mercados com pouca possibilidade para novos entrantes, pois são necessários elevados níveis de investimento, sendo as empresas mais afetadas pelos níveis de incertezas e complexidades que norteiam o mercado, tais como a flutuação dos indicadores econômicos, cenários de fornecedores, de Governo, de inflação, logística e políticas governamentais, por exemplo.

Quantos às contingências internas do grupo econômico, tiveram destaque aquelas que são características do tipo de negócio, como a necessidade de fornecer produtos a baixo custo, possuir um canal de distribuição amplo e com capacidade de disponibilizar rapidamente o produto para o cliente, o uso de equipes multifuncionais de trabalho para a execução de tarefas, os programas de qualificação dos gestores e a estrutura funcional ou adaptável, e ainda, admite-se a importância de atuar junto à sociedade, zelar por gerações futuras, ter orgulho de ações sociais e ambientais, usar o marketing como ferramenta de valorização das ações voltadas à RSC e de posicionar o grupo econômico entre as organizações com as melhores práticas sustentáveis, demonstrando a preocupação da organização para com a sociedade e com a credibilidade das marcas com as quais trabalha.

Quanto ao construto de configuração do SCG, as variáveis não financeiras possuem alto grau de confiança por parte do grupo econômico de grande porte, chegando a ser superior a algumas variáveis financeiras. No geral quase todas as variáveis, financeiras e não financeiras, possuem elevado grau de confiança, o que demonstra que o grupo econômico pesquisado usa intensamente os artefatos contábeis mais conhecidos na literatura e também os indicadores não financeiros mais comuns e importantes ao mercado em que atua, demonstrando a solidez da contabilidade gerencial dentro da organização, a qual contribui no direcionamento da alta direção por meio de indicadores, sejam econômicos, patrimoniais, financeiros e não financeiros.

A seguir, são apresentadas as recomendações da presente pesquisa, baseadas nas conclusões encontradas e também nas limitações da metodologia usada.

\subsection{RECOMENDAÇÕES}

A presente pesquisa objetivou avaliar a influência de fatores contingenciais sobre a configuração e mutação do sistema de controle gerencial de um grupo econômico e contribuiu para confirmar a importância e influência dos fatores contingenciais internos e externos sobre o desenho da organização do SCG do grupo econômico de grande porte, além de confirmar a influência da configuração do SCG sobre a mutação do SCG.

No entanto, fez-se necessário realizar algumas limitações no estudo, as quais podem ser exploradas em futuras pesquisas, a fim de aprimorar o campo de estudo da contabilidade gerencial, onde os resultados se basearam na percepção dos gerentes e diretores da organização, sendo possível ampliar os respondentes, o que torna possível obter resultados diferenciados por nível hierárquico do respondente. Outra limitação refere-se à amostra não probabilística, o que pode não representar adequadamente a população e ainda a não inclusão de outros fatores contingencias existentes.

Como contribuição, a presente pesquisa auxilia no aprimoramento de estudos voltados para áreas de contabilidade gerencial, os quais ainda são escassos no Brasil. Contribui também para o grupo econômico de grande porte, objeto do estudo, onde ficaram evidenciados os pontos fortes da organização no que diz respeito aos fatores contingenciais internos, à configuração e mutação do 
SCG, assim como foram identificadas algumas oportunidades a serem exploradas em futuras ocasiões, como a menor utilidade informada para o benchmarking interno. Outra oportunidade relevante para a organização é a menor importância dada ao BSC e ao fato de o sistema de informação possuir dados financeiros e não financeiros relacionados à relatórios de RSC.

\section{REFERENNCIAS}

ALMEIDA, D.; SANTOS, M. A. R.; COSTA, A. F. B. Aplicação do coeficiente de Cronbach nos resultados de um questionário para avaliação de desempenho da saúde pública. XXX Encontro Nacional de Engenharia de Produção. São Carlos, SP, out, 2010.

ATKINSON, A. A.; et. al. Contabilidade Gerencial. 3. ed. São Paulo: Atlas, 2011.

BEUREN, I. M.; ZONATTO, V. C. S. Evidenciação das características básicas recomendadas pelo COSO (2004) para a gestão de riscos em ambientes de controle no relatório da administração de empresas brasileiras com ADRs. XIII SemeAD, Seminários de Administração, set, 2010.

BRAMBILLA, F. R. Modelagem de equações estruturais: exemplo comentado da aplicação mediante a utilização do software AMOS. Revista INGEPRO, v. 3, n. 4, abr-2011.

CINTRA, Y. C. A integração da sustentabilidade às práticas de controle gerencial das empresas no Brasil. Tese de doutorado. Universidade de São Paulo. 2011.

DAHLSRUD, A. How corporate social responsbility is defined: na analisys of 37 definitions. Corporate and Social Responsibility and Environmental Management, v. 15, p. 1-13, 2008.

ESPEJO, M. M. S. B. Perfil dos atributos do sistema orçamentário sob a perspectiva contingencia: uma abordagem multivariada. Tese de Doutorado. Universidade de São Paulo. 2008.

FREZATTI, F. Management accounting profile of firms located in Brazil: a field study. Brazilian Administration Review, v. 2, n. 1, p. 73-87, 2005.

HALL, R. J.; COSTA, V. C.; KREUZBERG, F.; MOURA, G. D.; HEIN, N. Contabilidade como uma ferramenta de gestão: um estudo em micro e pequenas empresas do ramo de comércio de Dourados-MS. Revista da Micro e Pequena Empresa, v. 6, n. 3, p. 4-17, 2012.

HANNAN, M. T.; FREEMAN, J. The population ecology of organizations. American Journal of Sociology, v. 82, n. 5, p. 929-964, mar, 1977.

HORA, H.R.M.; MONTEIRO, G.T.R.; ARICA, J. Confiabilidade em questionários para qualidade: um estudo com o coeficiente alfa de Cronbach. Revista Produto \& Produção, v. 11, n. 2, p. 85-103, jun, 2010.

ISIDORO, C.; FACCI, N.; ESPEJO, M. M. S. B.; GARCIAS, P. M. A utilização de artefatos de contabilidade gerencial em cooperativas agropecuárias. Revista de Contabilidade da UFBA, v. 6, n. 2, 2012.

JUNQUEIRA, E. R. Perfil do sistema de controle gerencial sob a perspectiva da teoria da contingência. Tese de Doutorado. Universidade de São Paulo. 2010.

LAWRENCE, P. R.; LORSCH, J. W. Organization and enviroment: managing differentiation and intregation. Boston Havard Press, 1967. 
MACHADO, M. R. As informações sociais e ambientais evidenciadas nos relatórios anuais das empresas: a percepção dos usuários. Tese de Doutorado. Universidade de São Paulo. 2010.

MARREWIJK, M. V. Concepts and definition of CSR and corporate sustainability: between agency and communion. Journal of Business Ethics, v. 44, p. 95-105, 2003.

MARTINS, R. R. R.; et al. Stakeholders e responsabilidade social corporativa sob a perspectiva da teoria da ecologia organizacional. Informe Econômico, ano 14, n. 29, abr. 2013.

ONU - Organização das Nações Unidas. Report of the world comission on enviroment and development: our common future. 1987.

OYADOMARI, J. C., CARDOSO, R. L.; MENDONÇA NETO, O. R.; LIMA, M. P. Fatores que influenciam a adoção de Artefatos de Controle Gerencial nas Empresas Brasileiras. Um Estudo Exploratório sob a ótica da Teoria Institucional. Revista de Contabilidade e Organizações, v. 2, n. 2, p. 55-70, 2008.

RODRIGUES, I. P. F. Tecnologia, organização e rentabilidade: um modelo para investigação empírica. Revista de administração de empresas, v. 24, n. 4, p. 63-69, 1984.

SIMONS, R. Levers of control: how managers use innovative control systems to drive strategic renewal. Boston: Havard Business School. 1995.

SOUTES, D. O. Uma investigação do uso de artefatos da contabilidade gerencial por empresas brasileiras. Dissertação de Mestrado. Universidade de São Paulo. 2006.

STROEHER, A. M.; FREITAS, H. O uso das informações contábeis na tomada de decisão em pequenas empresas. Revista RAUSP, v. 1, n. 1, art. 7, 2008.

THOMPSON, J. D. Organizations in action. New York: Mcgraw Hill, 1967.

TURETA, C. ROSA, A. R. ÁVILA, S. C. Da teoria sistêmica ao conceito de redes interorganizacionais: um estudo exploratório da teoria das organizações. Revista de Administração da UNIMEP, v. 4, n. 1, jan.abr, 2006.

VALERIANO, C. E. B. Ciclo de vida organizacional e artefatos de contabilidade gerencial: uma investigação nas 250 pequenas e médias empresas que mais cresceram no Brasil entre 2008 e 2010. Dissertação de Mestrado. Universidade de São Paulo. 2012.

WENTING, R.; FRENKEN, K. Firm entry and institutional lock-in: na organizational ecology analysis of the global fashion design industry. Industrial and Corporate Change, v. 20, n. 4, p. 1031-1048, jun, 2011.

YIN, Robert K. Estudo de Caso: Planejamento e Métodos. 4. ed. Porto Alegre: Bookman, 2010. 